\title{
In utero transplantation of human hematopoietic stem/ progenitor cells partially repairs injured liver in mice
}

\author{
HUI QIAN $^{1}$, JUAN WANG, SHU WANG, ZHIJUAN GONG, \\ MEIJUE CHEN, ZHAORUI REN and SHUZHEN HUANG \\ Shanghai Institute of Medical Genetics, Shanghai Children's Hospital, Shanghai Jiao Tong University, Shanghai, P.R. China
}

Received March 13, 2006; Accepted May 12, 2006

\begin{abstract}
The aim of this study is to establish a novel mouse model with high achievement and chimerism by in utero transplantation of human hematopoietic stem/progenitor cells and to explore the possibility that human adult hematopoietic stem/progenitor cells can differentiate into hepatocyte-like cells and partially repair the liver damage induced by carbon tetrachloride $\left(\mathrm{CCl}_{4}\right)$. Mononuclear cells $(\mathrm{MNCs})$ were isolated from fresh human umbilical cord blood (hUCB) and CD34+ cells were enriched from the MNCs by magnetic cell isolation. These cells were injected respectively into the fetal mice at 11-13 days of gestation. At one month after birth, the specific markers of human cells, human $\alpha$-satellite sequence (h17 $\alpha$ ), CD14, CD34, CD45, and GPA were detected by PCR and FACS. At three and six months after birth, the established human-mouse chimeras were administered with $\mathrm{CCl}_{4}$ by intraperitoneal injection. The biochemical markers (ALT, AST, ALP, albumin) in serum were determined and human
\end{abstract}

Correspondence to: Dr Shushen Huang, Shanghai Institute of Medical Genetics, Shanghai Children's Hospital, Shanghai Jiao Tong University, 24/1400 West Beijing Road, Shanghai 200040, P.R. China

E-mail: szhuang1@yahoo.com; ytzeng@stn.sh.cn

Present address: ${ }^{1}$ School of Medical Technology, Jiangsu University, Zhenjiang, P.R. China

Abbreviations: AFP, $\alpha$ fetoprotein; ALB, albumin; ALP, alkaline phosphatase; ALT, alanine aminotransferase; AST, aspartic acid aminotransferase; $\beta-2 \mathrm{M}, \beta-2$ microglobulin; $\mathrm{BM}$, bone marrow; BSA, bovine serum albumin; $\mathrm{CCl}_{4}$, carbon tetrachloride; DAPI, 4',6-diamidino-2-phenylidole; FACS, fluorescence-activated cell sorting; FAH, fumarylacetoacetate hydrolase; FITC, fluorescein isothiocyanate; GPA, glycophorin A; $\mathrm{H} \& \mathrm{E}$, hematoxylin and eosin; $\mathrm{HNF} 4$, hepatocyte nuclear factor- $4 ; \mathrm{H}_{2} \mathrm{O}_{2}$, hydrogen peroxide; HSA, specific hepatocyte antigen; HSCs, hematopoietic stem cells; hUCB, human umbilical cord blood; IUT, in utero transplantation; $\mathrm{mAb}$, monoclonal antibody; MNCs, mononuclear cells; $\mathrm{PB}$, peripheral blood; PBS, phosphate-buffered saline; PCR, polymerase chain reaction; $\mathrm{PE}$, phycoerythrin; TDO, tryptophan 2,3-dioxygenase

Key words: human cord blood, hematopoietic stem/progenitor cells, in utero transplantation, hepatocyte, damage, repair hepatocyte-specific proteins, such as human albumin, hepatocyte nuclear factor-4, hepatocyte specific antigen, tryptophan 2,3-dioxygenase and $\alpha$ fetoprotein were analyzed by PCR, RT-PCR, real-time PCR and immunohistochemistry staining, respectively. More than $77 \%$ of recipients demonstrated human-mouse chimera. Significantly, hUCB hematopoietic stem/progenitor cells may differentiate into human hepatocytelike cells with evidence of the expression of human hepatocytespecific proteins as well as partially repair or protect liver damage induced by $\mathrm{CCl}_{4}$. The mouse model described in this article provides a useful tool for the studies of regeneration of human hepatocyte-like cells from adult hematopoietic stem/ progenitor cells as well as facilitates the therapeutic potential for liver diseases or damage by in utero transplantation.

\section{Introduction}

The potential to treat the fetus with a birth defect by in utero transplantation (IUT) of hematopoietic stem cells has been reported (1). This approach may have several advantages, such as: i) the rapid growth of fetus provides opportunity for engraftment and expansion of donor cells; ii) fetal immunologic immaturity and the potential for induction of donor-specific tolerance; iii) the sterile and protective fetal environment provides isolation from environmental pathogens; iv) early treatment of diseases is beneficial or critical for effectiveness (2), and hematopoietic stem cells (HSCs) have the capacity to self-renew, trans-differentiate and regenerate tissues and organ systems. These assumptions were first supported by Owen's findings in 1945 (3) that dizygotic cattle twins who shared cross placental circulation were born chimeric for their sibling's blood elements. The chimerism persists for life and is associated with donor-specific transplantation tolerance. Similar results have also been observed in other species, most notably, humans (4) and cotton top tamarin (5). In the past decade, the multilineage hematopoietic chimerism in fetal mouse was well documented after adult bone marrow (BM) derived HSC transplantation (6,7) and human cord blood transplantation $(8,9)$. In addition, we established an experimental model of in utero transplantation of human hematopoietic stem cells into fetal goats under B-scan ultrasonography. This model is useful for the study of potential prenatal therapy $(10,11)$.

Many authors have reported that multipotent stem cells of bone marrow or umbilical cord blood gave rise to hepatocytes, 
endothelial cells and muscle (9,11-13). These experiments have demonstrated that multipotent stem cells (or their progeny) have the characteristics of unexpected plasticity or transdetermination when located in ectopic environments. Few mechanisms have been elucidated, but these findings have been applied to therapy for various diseases and tissue or organ damage in animal models. For instance, Peterson et al firstly reported that rodent BM cells were able to give rise to oval cells and hepatocytes on transplantation into lethally irradiated rats (14). Moreover, a number of successful studies on stem cell plasticity in vivo usually depended on immunodeficiency or fumarylacetoacetate hydrolase (FAH) deficient mice $(15,16)$. Similarly in utero transplantation of human hematopoietic stem cells is a successful therapeutic model for immunodeficiency disorders in which there is a clear selective advantage for donor cells. However, it is mostly unknown what happens in normal (uninjured) animals with in utero transplantation of human hematopoietic stem/ progenitor cells. Can human hematopoietic stem/progenitor cells be transdifferentiated into human oval cells or hepatocytes in the recipient animals? Thus the purpose of the current investigation is to establish a novel mouse model which has high harvest and chimerism via in utero transplantation of hUCB-derived primitive hematopoietic cells, and to explore the possibility of the differentiation of the donor human cells into hepatocytes as well as the repair of liver damage induced by $\mathrm{CCl}_{4}$.

\section{Materials and methods}

Preparation of donor cells. Human primitive hematopoietic cells were collected and purified from umbilical cord blood (UCB) after informed consent was obtained from the mothers. The mononuclear cells (MNCs) were treated as described previously $(10,11)$. Briefly, MNCs were isolated by Lymphoprep $^{\text {TM }}(1.077 \mathrm{~g} / \mathrm{ml}$; Nycomed Pharma AS, Oslo, Norway) density gradient centrifugation, and $\mathrm{T}$ cells were partially depleted prior to transplantation. $\mathrm{CD}^{+} \mathrm{T}$-cell depletion was performed by incubation of washed cells with biotinconjugated anti-human CD3 monoclonal antibody (mAb; Pharmingen, San Diego, CA). CD34+ cells were enriched from MNCs by magnetic activated cell sorting with a CD34 progenitor cell isolation kit (Miltenyi Biotec, Bergish Gladbach, Germany). The cells were counted prior to transplantation and more than $95 \%$ of viability was confirmed by trypan blue exclusion.

Mice. Mice (KunMingBai strain, 8-10 weeks old) were obtained from the animal facility of Shanghai Institute of Medical Genetics, Shanghai Children's Hospital, and their utilization was approved by the Review Board of Shanghai Children's Hospital. Animals were mated and the females were then checked for vaginal plugs daily. The day when the vaginal plug was identified was designated as day 0 . Then the pregnant females were bred alone till the day of transplantation. Fetuses of time-dated pregnant mice were injected at day 11 to 13 of gestation (term gestation 21 days). At three months after transplantation, six human-mouse chimeras that had been identified by polymerase chain reaction (PCR) and fluorescence-activated cell sorting (FACS) were subjected to liver damage by intraperitoneal administration of $5 \mathrm{ml} / \mathrm{kg}$ $\mathrm{CCl}_{4}$ diluted to $100 \mu \mathrm{l}$ with corn oil (Sigma, St Louis, MO). Untransplanted mice were used as control.

In utero transplantation of human hematopoietic stem/ progenitor cells. hUCB-derived MNCs or CD $34^{+}$cells were injected directly into the fetal peritoneal cavity of pregnant mice. On day 11 to 13 after mating, pregnant mice were anesthetized with $1 \%$ pentobarbital sodium $(7 \mathrm{ml} / \mathrm{kg}$ body weight) and the uterine horns were exposed by a midline abdominal incision. Each fetus was administered intraperitoneally with $1 \times 10^{6} \mathrm{MNCs}$ or $1 \times 10^{4} \mathrm{CD} 34^{+}$cells in $5 \mu 1$ phosphate-buffered saline (PBS). Control animals received $5 \mu \mathrm{l}$ PBS rather than donor cells. The mothers were kept warm until they recovered from anesthesia. The pups were subsequently weaned at 3 weeks of age.

Fluorescence-activated cell sorting (FACS) for assessment of human cell surface markers. FACS analysis was performed after birth at intervals until the mice were sacrificed. Approximately $300 \mu 1$ of peripheral blood was collected in heparinized capillary tubes via retro-orbital vein puncture of mice. The blood was then analyzed with flow cytometric analysis to determine the presence of human hematopoietic cells. Phycoerythrin (PE)- or fluorescein isothiocyanate (FITC)-conjugated monoclonal antibodies (mAbs) specific for human $\mathrm{CD}$ antigens (CD14, CD34, CD45) and glycophorin A (GPA) were purchased from Becton-Dickinson Immunocytometry Systems (San Jose, CA, USA) and used according to the manufacturers' instructions. Several irrelevant isotype-matched mAbs (BectonDickinson) were used as negative controls. The cells were incubated with saturating amounts of corresponding mAbs for $30 \mathrm{~min}$ in the dark at room temperature $\left(20-25^{\circ} \mathrm{C}\right)$, followed by hemolysis and two washes prior to the analysis with FACSCalibur (Becton-Dickinson). The tested cell counts were $1 \times 10^{5}$. Duplicated measurements were performed for each sample.

The transplanted mice were sacrificed at various times and human cell engraftment in the bone marrow (BM), spleen, and peripheral blood $(\mathrm{PB})$ of the mice was analyzed by flow cytometry. Bone marrow cells were obtained by flushing both the removed femurs and tibiae of mice. Single cell suspensions were prepared from the removed spleens passed through a nylon filter to remove debris.

Molecular analysis of human genomic DNAs. DNA was extracted from blood cells of recipient mice. CD34, GPA, and CD45 were detected by nested-PCR procedure using sequencespecific primers (CD34 primers: S1, 5'-CATGGAGCTCAGT GGAACTTAG-3'; A1, 5'-ATGCTGGAGGTGACATCTCT-3'; S2, 5'-CTGGTGACCAAGTCCACAGT-3'; A2, 5'-CACCTC AGAGGCTGTTCTTG-3'; GPA primers: S1, 5'-TATGTCC ACGCAGTCACCTC-3'; A1, 5'-CCACAGCCACTGTCTG AATC-3'; S2, 5'-GGACACATATGCAGCCACTC-3'; A2, 5'-CTGTTCCACCTGTGCTAACC-3'; CD45 primers: S1, 5'AACGCTTCTCGAAGCAGTGA-3'; A1, 5'-GGAGGTTTG GAGTTTCCTCA-3'; S2, 5'-CCTGCTCAGAATGGACAA GT-3'; A2, 5'-CTTGCAGGACCATTGACAGA-3'). The amplification of sequence was as follows. In the first PCR, $15 \mu 1$ of PCR mixture contained primer $\mathrm{S} 1, \mathrm{~A} 1$. After initial 
denaturing at $94^{\circ} \mathrm{C}$ for $5 \mathrm{~min}, 18$ cycles were performed, including $1 \mathrm{~min}$ at $94^{\circ} \mathrm{C}, 45 \mathrm{sec}$ at $61^{\circ} \mathrm{C}$ or $55^{\circ} \mathrm{C}, 1 \mathrm{~min}$ at $72^{\circ} \mathrm{C}$, and a final extension at $72^{\circ} \mathrm{C}$ for $10 \mathrm{~min}$. In the second PCR amplification, $25 \mu 1$ of mixture contained primer $\mathrm{S} 2, \mathrm{~A} 2$ and $5 \mu 1$ of the first PCR products. PCR conditions were similar to those of the first PCR except for the annealing for $30 \mathrm{sec}$. In total, 28 cycles were performed. As inter-matched control, the primers of $B$-actin were as follows: S, 5'-CGCTC GTTGCCAATAGTGAT-3'; and A, 5'-CCACAGGCATTGT GATGG-3', annealing at $60^{\circ} \mathrm{C}$ and 28 cycles.

Additionally, human chromosome 17-specific $\alpha$-satellite sequences (h17 $\alpha$ primers: S, 5'-ACACTCTTTTTGCAGGAT CTA-3'; A, 5'-AGCAATGTGAAACTCTGGGA-3') was also identified with PCR (17). DNA samples (200 ng) were subjected to PCR for a 1171-bp human fragment under the following conditions: $94^{\circ} \mathrm{C}$ for $5 \mathrm{~min}$ ( 1 cycle), denaturing at $94^{\circ} \mathrm{C}$ for $1 \mathrm{~min}$, annealing at $64^{\circ} \mathrm{C}$ for $1 \mathrm{~min}$ and extending at $72^{\circ} \mathrm{C}$ for $2 \mathrm{~min}$ for 40 cycles. The final extension step was at $72^{\circ} \mathrm{C}$ for $10 \mathrm{~min}$ and then kept at $4^{\circ} \mathrm{C}$. The products were separated in $2.0 \%$ agarose gel and visualized by ethidium bromide staining.

Real-time PCR was performed to detect the human CD34 gene with RG3000 quantities (Corbett Research, Australia). The probe for human CD34 DNA was FAM-5'-ATACGCAC AAACGGG-3'-MAB and the primer pair was 5'-TGCTCT CTTGTAATGATATAGCCAGAA-3' and 5'-CTTGGAGG AGAGATGAGGGAAGT-3'. The reaction condition was as follows: after an initial denaturation at $95^{\circ} \mathrm{C}$ for $5 \mathrm{~min}, 35$ cycles of $95^{\circ} \mathrm{C}$ for $30 \mathrm{sec}$ and $59^{\circ} \mathrm{C}$ for $30 \mathrm{sec}$ were performed. Fluorescence was then detected at $585 \mathrm{~nm}$ and $59^{\circ} \mathrm{C}$ for each step. All of the samples were repeated in triplicate for each experiment. Tandem dilution curves were also plotted based on the known quantities of standard plasmid containing human CD34 DNA. Mouse SRY was considered as the reference gene (primers, 5'-TCAGCAAGCAGCTGGGATG-3' and 5'GGGCCTTTTTTCGGCTTC-3'; and probe, FAM-5'-AGGT GGAAAAGCCTTAC-3'-MAB).

Histological and immunohistochemical analysis. After 1 month of $\mathrm{CCl}_{4}$ treatment, mice were sacrificed and then perfused with saline solution by cardiac puncture under anesthesia to wash out circulating blood cells residing in organs. Livers were obtained for histological and immunohistochemical analysis and molecular detection. Positive controls were normal human tissue obtained under informed consent. The liver specimens were fixed in $4 \%$ formaldehyde and paraffin-embedded. Sections (5 $\mu \mathrm{m}$ in thickness) were adsorbed on polylysinecoated glass slides, air-dried, deparaffinized, and then placed in a water bath. The sections were stained by hematoxylin and eosin (H\&E) or treated with heating for antigen retrieval. For peroxidase-linked immunostaining, endogenous peroxidase was removed by $0.3 \%$ hydrogen peroxide $\left(\mathrm{H}_{2} \mathrm{O}_{2}\right)$ in methanol for $5 \mathrm{~min}$. Nonspecificities were blocked by $5 \%$ normal horse serum (Vector Laboratories Inc.) in antigen dilution (Dako, Glostrup, Denmark). The liver specimens were incubated with rabbit antibodies against human albumin and human $\alpha$ fetoprotein (diluted 1:50; Dako), mouse monoclonal antibodies against human HSA (1:50; Dako) in an appropriate concentration. Endogenous mouse IgG was blocked using the mouse-on-mouse immunodetection kit (Vector) according to the manufacturer's instructions, incubated with biotinylated secondary antibodies (1:300) and then with diaminobenzidine tetrahydrochloride solution (DAB kit, Vector Labs) for $5 \mathrm{~min}$. The sections were washed, counterstained in hematoxylin for nuclear staining, mounted and observed under light microscope (TE2000, Nikon).

For immunofluorescence staining on paraffin sections, the liver tissues were fixed overnight with $4 \%$ paraformaldehyde at $4{ }^{\circ} \mathrm{C}$, and permeabilized with $0.5 \%$ Triton X-100 (SigmaAldrich) for $60 \mathrm{~min}$. Slides were blocked by $1 \%$ bovine serum albumin (BSA) with $0.05 \%$ Tween-20 for $60 \mathrm{~min}$ and incubated with rabbit primary antibodies against human albumin (1:50) and $\beta-2$ microglobulin ( $\beta-2 \mathrm{M}, 1: 200$; Dako) for $1 \mathrm{~h}$, followed by FITC-coupled goat anti-rabbit immunoglobulin $\mathrm{G}$ as the secondary antibody for $1 \mathrm{~h}$. Between incubations, the samples were washed with phosphate-buffered saline. The nuclei were counterstained with 4',6-diamidino-2-phenylidole (DAPI; Sigma-Aldrich).

Biochemical assays and enzyme linked immunosorbant assay (ELISA). Murine sera were collected to analyze alanine aminotransferase (ALT), aspartic acid aminotransferase (AST), alkaline phosphatase (ALP) and albumin (ALB). After three months of receiving human cord blood cells, the transplanted mice were treated with $\mathrm{CCl}_{4}$ administration. At the fourth week after $\mathrm{CCl}_{4}$ damage the plasma of mouse was collected and human serum albumin was assayed by ELISA. Untransplanted murine sera as controls were tested and all samples were run in triplicate.

Detection of the expression of human hepatocytic specific transcripts by reverse transcriptase-polymerase chain reaction $(R T-P C R)$. Total RNA was extracted from the human-mouse chimeric liver, murine liver, human liver and starting human cellular populations by TRIZOL reagents (Invitrogen, Carlsbad, CA). RNA in the samples was quantitated using a biophotometer (Eppendorf, Germany) and equal amounts of RNA from all samples were reverse transcribed into single-stranded cDNA by using reverse transcriptase and oligo dT primers according to the manufacturer's recommendations. Human or mouse-specific albumin (ALB, human ALB primers: S, 5'TTGCCAAGCTGCTGATAAGG-3'; A, 5'-ATGGCAGCAT TCCGTGTG-3'; mouse ALB primers: S, 5'-GTTGTGCAGA GGCTGACAAG-3'; A, 5'-TAGCAAGTCTCAGCAACAGG -3'; human/mouse ALB primers: S, 5'-AATGAAGTGGGTA ACCTTT-3'; A, 5'-GGGTTGTCATCTTTGTGT-3'), human hepatocyte nuclear factor-4 (HNF4, primers: S, 5'-CTGCTG GTTCTCGTTGAGTG-3'; A, 5'-TTGGCATCTGGGTCAA AG-3') and tyrptophan 2,3-dioxygenase (TDO, primers: S, 5'ACCTCCGTGCTTCTCAGACA-3'; A, 5'-GGAAGCCTGA TGCTGGAGAT-3') were used to detect the expression of human genes in mouse liver. For amplification, the reaction was hot-started for denaturation at $94^{\circ} \mathrm{C}$ for $5 \mathrm{~min}$, followed by 40 cycles of denaturation at $94^{\circ} \mathrm{C}(1 \mathrm{~min})$, annealing at $55-62^{\circ} \mathrm{C}(45 \mathrm{sec})$ and elongation at $72^{\circ} \mathrm{C}(1 \mathrm{~min})$. The primer of $B$-actin for RT-PCR was as follows: S, 5'-CTACAATGAG CTGCGTGTGGC-3'; A, 5'-CAGGTCCAGACGCAGGATG GC-3'. The products were examined by $3 \%$ Nusieve agarose gel electrophoresis. RNA analyses were repeated 3 times using different samples and similar results were obtained. 



Figure 1. FACS analysis for surface antigens of human hematopoietic cells in various organs of recipient at the 11th month of age. In PB, approximately $7.4 \%$ and $5.4 \%$ of the PB cells were positive for GPA and CD45. In BM, approximately $7.5 \%$ of the BM cells were positive for GPA, merely $0.4 \%$ of cells were positive for CD45. In spleen, $8.2 \%$ of cells were positive for GPA, but $0.2 \%$ of cells were positive for CD45.

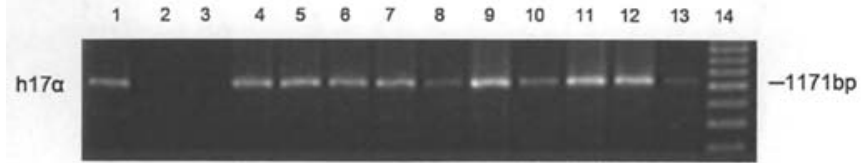

Figure 2. PCR for human specific DNA sequence h17 $\alpha$ in transplanted and untransplanted mice. Lane 1, human; lanes 2 and 3, untransplanted mice; lanes 4-8, 5 transplanted mice with MNC injection; lanes 9-13, 5 transplanted mice with $\mathrm{CD}_{3} 4^{+}$cell injection; lane 14, DNA-marker.

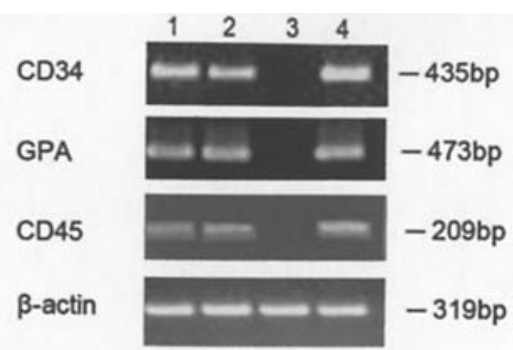

Figure 3. PCR analysis for human genes of CD34, GPA, and CD45 in transplanted and untransplanted mice. Lane 1, transplanted mouse with MNC injection; lane 2, transplanted mouse with $\mathrm{CD}_{3} 4^{+}$cell injection; lane 3, untransplanted mouse; lane 4 , human.

Statistical analysis. All the data were represented by plotting the mean value and standard deviation of each group. Statistical comparisons between the groups were performed by chi-square

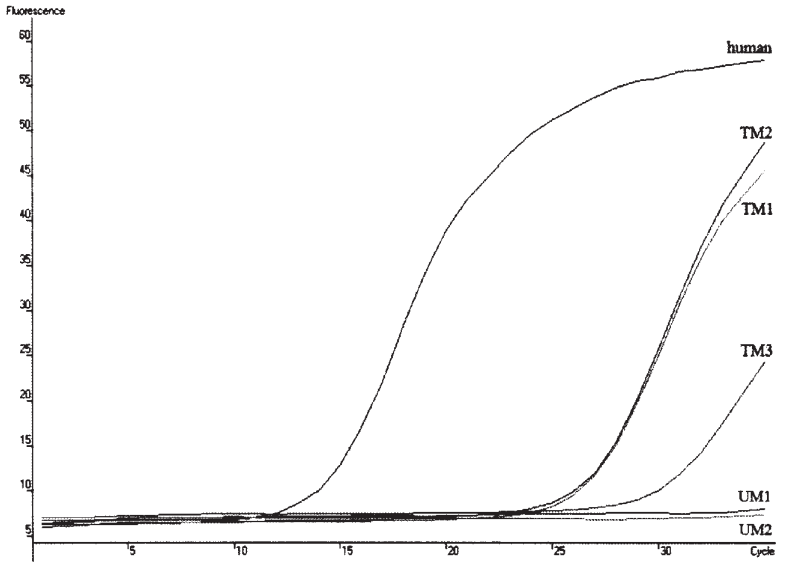

Figure 4. Real-time PCR for detection of human CD34 in transplanted male mice. The panel showed fluorescence versus cycle number for human CD34 gene from a normal human sample $\left(1.29 \times 10^{6} \mathrm{copies} / \mu \mathrm{g}\right.$ genomic DNA), and three transplanted mice $\left(2.24 \times 10^{2}-2.46 \times 10^{3}\right.$ copies $/ \mu \mathrm{g}$ genomic DNA). Human CD34 was not detectable in two untransplanted mice.

test or two-tailed Student's t-test assuming unequal variances and a P-value of $<0.05$ was considered significant.

\section{Results}

Survival rate of transplanted mice. In the transplanted mouse group, 11 pregnant mice received the in utero transplantation 
Table I. Survival data after in utero transplantation of human hematopoietic stem/progenitor cells in normal mice.

\begin{tabular}{lccccc}
\hline Groups & $\begin{array}{c}\text { Cells injected } \\
\text { per fetus }\end{array}$ & $\begin{array}{c}\text { No. of fetuses } \\
\text { injected }\end{array}$ & $\begin{array}{c}\text { No. of natal pups } \\
(\%)\end{array}$ & $\begin{array}{c}\text { No. of live-born } \\
\text { pups }\end{array}$ & $\begin{array}{c}\text { Survival rate } \\
(\%)\end{array}$ \\
\hline MNC & $1 \times 10^{6}$ & 30 & $17(57)$ & 13 & 43 \\
CD34 $^{+}$ & $1 \times 10^{4}$ & 34 & $12(35)^{*}$ & 9 & 26 \\
PBS (control) & & 34 & $21(62)$ & 16 & 47 \\
\hline
\end{tabular}

${ }^{*} \mathrm{P}<0.05$ (compared to control groups).

Table II. FACS analysis of human donor cell engraftment in mice.

Human cell frequency $(\%)$

\begin{tabular}{lcccc}
\hline Human cell markers & CD34 & GPA & CD14 & CD45 \\
Engrafted $(n=17)$ & $2.44 \pm 0.51$ & $3.74 \pm 0.83$ & $2.20 \pm 0.62$ & $0.76 \pm 0.30$
\end{tabular}

Each value (mean $\pm \mathrm{SE}$ ) represents the percentage of a specific cell subpopulation of human origin in the blood of recipients three months after birth as detected by FACS analysis. No human cells were detectable in untransplanted mice $(\mathrm{n}=6)$.

Table III. Analysis and detection of human CD34 and mouse SRY DNAs in transplanted mouse blood using quantitative real-time PCR.

\begin{tabular}{lccc}
\hline Sample & $\begin{array}{c}\text { hCD34 gene } \\
\text { copies/ } \mu \text { g DNA }\end{array}$ & $\begin{array}{c}\text { mSRY gene } \\
\text { copies/ } \mu \text { g DNA }\end{array}$ & $\begin{array}{c}\text { hCD34 copies/ } \\
\text { mSRY copies }\end{array}$ \\
\hline TM 1 & $5.07 \times 10^{2}$ & $2.75 \times 10^{5}$ & $1.84 \times 10^{-3}$ \\
TM 2 & $2.46 \times 10^{3}$ & $6.74 \times 10^{5}$ & $3.65 \times 10^{-3}$ \\
TM 3 & $2.24 \times 10^{2}$ & $1.60 \times 10^{6}$ & $1.40 \times 10^{-4}$ \\
Human & $1.29 \times 10^{6}$ & 0 & \\
UM 1 & 0 & $1.46 \times 10^{6}$ & 0 \\
UM 2 & 0 & $2.86 \times 10^{5}$ & 0 \\
\hline
\end{tabular}

Proportion of human cells in peripheral blood of transplanted male mice by real-time PCR is analysed. The copy numbers of human CD34 (hCD34) are calculated from a normal human sample and three transplanted mice. Cell numbers per $\mu \mathrm{g}$ genomic DNA are estimated by the copy numbers of mouse SRY (mSRY). TM, transplanted mouse; $\mathrm{UM}$, untransplanted mouse; hCD34, human CD34; mSRY, mouse SRY.

of donor cells in 11-13 days of gestation. Three pregnant mice miscarried and the abortion rate was $27 \%$ (3/11), which was similar to that of the untransplanted control group in which the abortion rate was $25 \%$ (1/4). By direct injection in early gestation, we had in utero transplanted hUCB derived MNCs into 30 fetal mice, 17 fetuses were born at term (21 days). In contrast to the negative group, the rates of misbirth and survival were not obviously different. In the $\mathrm{CD} 34^{+}$group, the rate of survival was not visibly different $(\mathrm{P}>0.05)$ but the rate of misbirth was significantly higher $(\mathrm{P}=0.0289, \mathrm{P}<0.05)$ (Table I).
The rate of chimerism in recipients. In order to confirm the stability of the donor cell engraftment, the transplanted animals were examined by serial flow cytometry at 1, 3, 6, 9 and 12 months of age. FACS analyses for the blood samples from the transplanted mice showed that the proportions of human $\mathrm{CD}_{3}{ }^{+}$cells were $2.44 \pm 0.51 \%$ (range, $0.2-8.7 \%$ ) and $\mathrm{GPA}^{+}$ (glycophorin A) cells were $3.74 \pm 0.83 \%$ (range, 0.5-12.1\%). $\mathrm{CD}_{14}{ }^{+}$were $2.20 \pm 0.62 \%$ (range, $0.4-11.4 \%$ ) and $\mathrm{CD} 45^{+}$were $0.76 \pm 0.30 \%$ (range, $0.1-5.4 \%$ ), respectively (Table II). These results revealed that 17 out of the 22 transplanted mice had human hematopoietic cell chimerism in their peripheral blood. There was no direct correlation in frequency between human $\mathrm{CD}^{+}{ }^{+}$cells and human $\mathrm{GPA}^{+}, \mathrm{CD}_{14}{ }^{+}$and $\mathrm{CD} 45^{+}$cells in the same mouse. Human $\mathrm{CD} 14^{+}, \mathrm{CD} 34^{+}, \mathrm{CD} 45^{+}$and $\mathrm{GPA}^{+}$cells were not found in peripheral blood from the control group of 6 untransplanted mice.

The surface markers in various organs of human-mouse chimera. The engraftment of human cells in a representative transplanted mouse was confirmed after 324 days of transplantation (Fig. 1). The mouse was sacrificed at the 324th day after hUCB-derived MNC transplantation. PB, BM and spleen cells of the mouse were treated with anti-human GPA, CD14, CD34 and CD45 antibodies. Human GPA+ (7.4-8.2\%) and $\mathrm{CD}_{4} 5^{+}(0.2-5.4 \%)$ cells were detectable in $\mathrm{PB}, \mathrm{BM}$ and spleen, but human CD14 and CD34 antigens were negative. The results suggested that engrafted cells could survive longterm. Duration of engraftment was confirmed to be more than 12 months.

The molecular characteristics of the human donor cell in recipient mice. The human chromosome 17 -specific $\alpha$-satellite sequence was detected in transplanted mice by PCR (Fig. 2). DNA sequencing analysis of the PCR products indicated an almost full identity (98\%) with the sequences provided by GenBank (M13882, X06646). Furthermore, several methods were performed to verify the existence and expansion of grafted human cells in recipient mice. Fig. 3 showed the DNAs of human CD34, CD45 and GPA presented in engrafted mice by PCR analysis. Likewise, the results of real-time quantitative PCR showed the presence of the human CD34 gene in the transplanted mice. The copies of human CD34 DNA in the peripheral blood of the chimera male recipients were detected by real-time PCR. The copies of the mouse SRY gene represented the numbers of whole cells (Table III and Fig. 4). The amplification of DNA from the untransplanted male mouse was negative. 
A
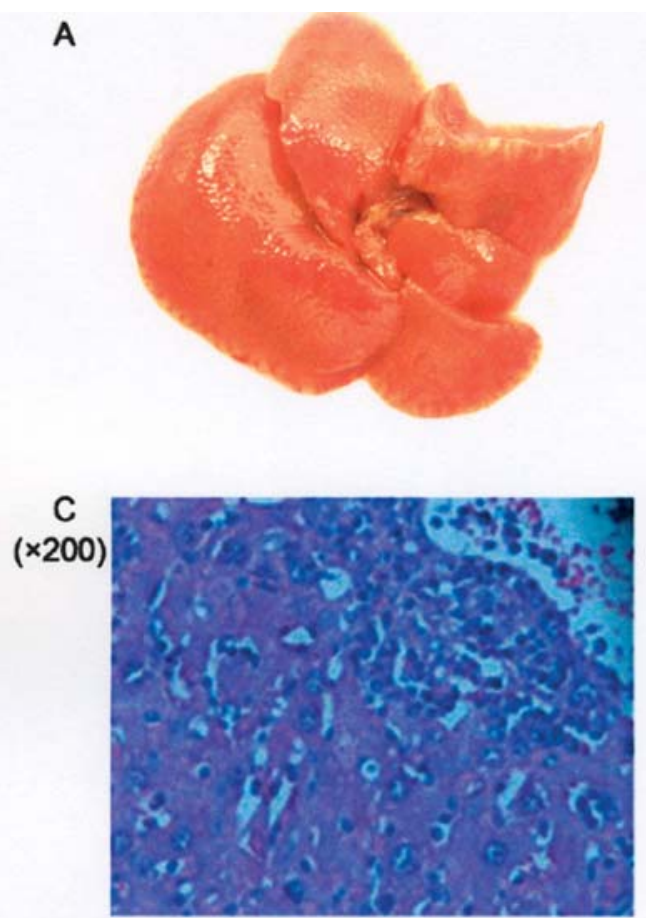

B

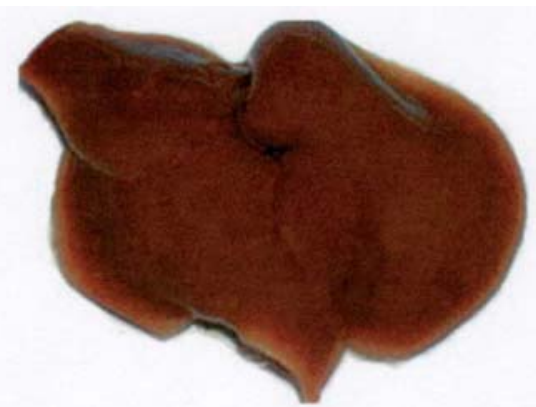

D
$(\times 200)$



Figure 5. Mouse liver damaged by $\mathrm{CCl}_{4}$ and $\mathrm{HE}$ staining. A, age-matched $\mathrm{CCl}_{4}$-treated liver of untransplanted mouse at 1 month. $\mathrm{B}$, $\mathrm{CCl}_{4}$-treated liver of engrafted mouse at 1 month. $\mathrm{C}, \mathrm{H} \& \mathrm{E}$ staining (untransplanted mouse liver after $\mathrm{CCl}_{4}$ treatment). D, $\mathrm{H} \& \mathrm{E}$ staining (transplanted mouse liver after $\mathrm{CCl}_{4}$ treatment). In untransplanted mouse, $\mathrm{CCl}_{4}$ induced massive liver damage in the form of numerous foci of periportal necrosis (A), $\mathrm{H} \& \mathrm{E}$ staining showed that the damaged liver tissues were infiltrated with a large number of inflammatory cells $(\mathrm{C})$. The liver of transplanted mouse after $\mathrm{CCl}_{4}$ treatment appeared smooth on the surface (B) and arranged normally, and inflammatory cells disappeared (D).

A
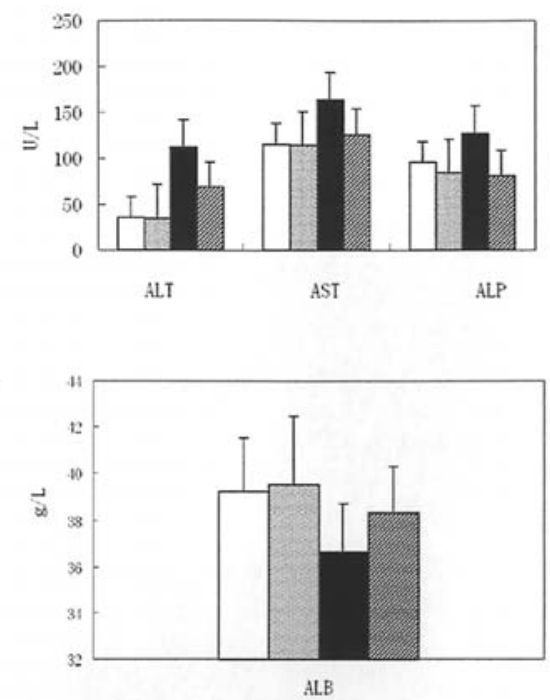

Quntransplanted mice

口transplanted mice

ecc14 treated untransplanted mice

accll treated transplanted mice

Figure 6. Changes in liver metabolic functions after $\mathrm{CCl}_{4}$ treatment. A, the level of alanine aminotransferase (ALT), aspartic acid aminotransferase (AST) and alkaline phosphatase (ALP) in sera of untransplanted mice after 2 weeks of $\mathrm{CCl}_{4}$ treatment exhibited a striking increase $(\mathrm{P}<0.01)$, but these parameters in sera of transplanted mice after 2 weeks of $\mathrm{CCl}_{4}$ treatment did not show noticeable changes $(P>0.05)(n=6)$. B, the level of ALB in sera of transplanted mice after 4 weeks of $\mathrm{CCl}_{4}$ treatment did not show significant changes $(P>0.05)(n=6)$, but the level of ALB exhibited a marked decrease in untransplanted mice $(\mathrm{P}<0.01)$.

Partial repair and protection of injured liver in transplanted mice. Compared with the liver of a normal age-matched mouse,

$\mathrm{CCl}_{4}$ induced massive liver damage in the form of numerous foci of periportal necrosis (Fig. 5A). The histological section with $H \& E$ staining showed that the structure of the liver was a mess. The damaged liver tissues were infiltrated with a large number of inflammatory cells, such as lymphocytes, monocytes, and neutrophiles (Fig. 5C). The liver of hUCB-engrafted mice after $\mathrm{CCl}_{4}$ treatment appeared smooth and glossy on the surface and showed mild damage (Fig. 5B). Compared with the damaged liver tissues shown in Fig. 5C, the liver tissues of hUCB-engrafted mice with $\mathrm{CCl}_{4}$ treatment were arranged normally and inflammatory cells disappeared (Fig. 5D). The results of biochemical analysis showed no noticeable changes of ALT, AST, ALP and ALB in the sera of transplanted mice after injury induced by $\mathrm{CCl}_{4}$, but these parameters showed a striking increase or decrease in untransplanted mice $(\mathrm{P}<0.01$, Fig. 6A and B). These results suggested that hUCB-derived hematopoietic stem/progenitor cells might relieve the liver damage caused by $\mathrm{CCl}_{4}$.

Human hepatocyte-like cells generated in vivo from $h U C B$ cells. Compared with $\mathrm{CCl}_{4}$-treated untransplanted mice (Fig. 7A), the liver tissue sections of the transplanted mice treated with the specific antibody against human albumin showed that there were a large number of cells with light brown coloration (Fig. 7B and C). Fig. 7E and F also showed that a number of cells were positive for hAFP in the sections of $\mathrm{CCl}_{4}$-treated livers (transplanted), but the control groups were negative (Fig. 7D). The result for HSA was similar to ALB and AFP (Fig. 7H and I). Most positive cells were located in the vicinity of vascular structures. 




Figure 7. Immunohistochemical staining for hALB, hAFP, and hHSA in $\mathrm{CCl}_{4}$-treated liver (untransplanted and engrafted). A, D and $\mathrm{G}$, stain for albumin (ALB), $\alpha$ fetoprotein (AFP) and specific hepatocyte antigen (HSA) in $\mathrm{CCl}_{4}$-treated liver (untransplanted), the results are negative (x200). B, E and $\mathrm{H}$, stain for $\mathrm{ALB}, \mathrm{AFP}$ and $\mathrm{HSA}$ in $\mathrm{CCl}_{4}$-treated liver (transplanted), there were a large number cells with light brown coloration (x200). C, F and I, magnified images of corresponding squared areas of $\mathrm{B}, \mathrm{E}$ and $\mathrm{H}$, respectively.

Immunofluorescence results showed that positive ALB of cytoplasmic staining and $\mathrm{B}-2 \mathrm{M}$ of cytoplasmic membrane staining were present in differentiated hepatocytes of the engrafted mice as well as in human samples, but negative in untransplanted mice (Fig. 8).

Human liver-specific gene expression. RT-PCR revealed the presence of a specific 317-bp fragment of human HNF-4 in human and transplanted mouse livers. No amplification was shown in the liver tissue of untransplanted mice. Similar results for hTDO mRNA were obtained by RT-PCR analysis, only a specific 493-bp fragment was found in human and transplanted mouse livers (Fig. 9).

The RT-PCR products in Fig. 10 showed that a specific human ALB mRNA (238 bp in length) was present in liver of chimeric mice. Human-specific albumin primers were used for RT-PCR in comparison with murine-specific albumin, and the amplification was halted in log phase. No expression of human albumin transcript was exhibited in the untransplanted mouse liver $\left(\mathrm{CCl}_{4}\right.$-treated), and no albumin expression either in human cord blood mononuclear cells.

Human serum albumin in the plasma of mice. Table IV shows that the level of human ALB in five engrafted mice sera was
1.5-15.6 mg/l measured by ELISA and was below $0.59 \mathrm{mg} / \mathrm{l}$ in untransplanted mice after $\mathrm{CCl}_{4}$ treatment. In one of the engrafted mice, the level of human ALB was 26-fold higher than that of untransplanted mice. This result was in agreement with those obtained from RT-PCR.

\section{Discussion}

The developmental stage of the fetal recipients and the source of donor cells are very important elements for successful in utero HSC transplantation. Our data showed that the frequency of chimerism was approximate to $77 \%$ (Table I), which was similar to other reports $(18,19)$. Oppenheim et al reported that the highest rate $(92 \%)$ of chimerism was observed among the recipients (goat) of MNCs isolated by low-density Ficoll (19). We selected the cell preparations derived from cord blood which contained rich primitive hematopoietic cells and poor mature lymphocytes to perform in utero transplantation into fetal mice and obtain a higher survival rate of chimerism in recipients of MNC groups. It was not clear why the misbirth rate of the $\mathrm{CD}_{3} 4^{+}$group was higher. We speculated that it might be associated with a lack of other accessory cells, such as stromal cells. In our experiments the recipients were normal animals. A proper stage of fetal development, which 

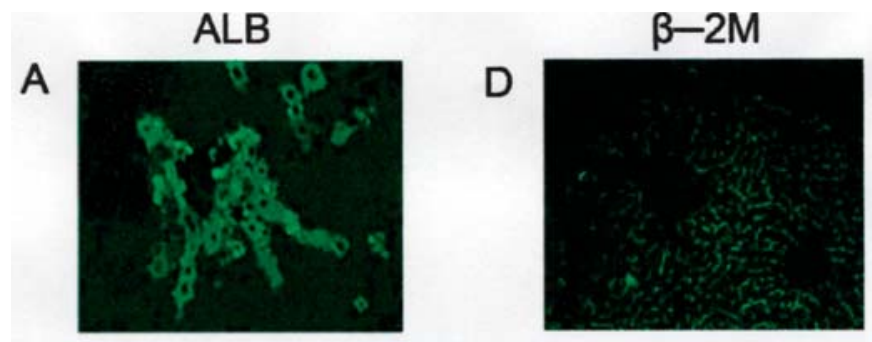

B

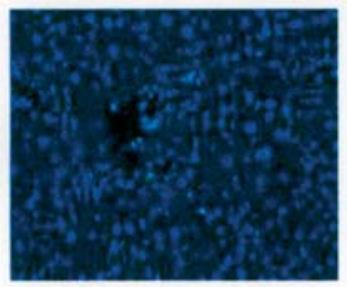

C

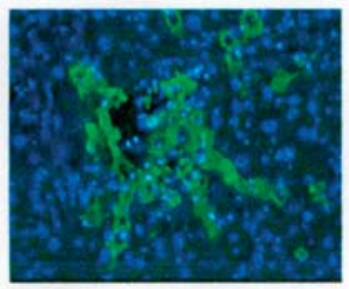

E



F

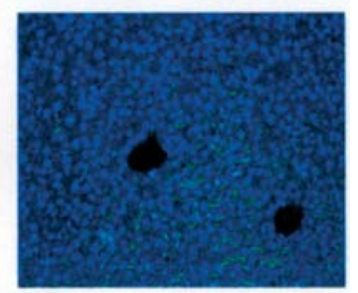

Figure 8. Immunofluorescent observation for human ALB and B-2M. A, stain for ALB in $\mathrm{CCl}_{4}$-treated engrafted mouse liver (x200). B, DAPI staining for nucleus. C, merge of A and B. D, stain for $\mathrm{B}-2 \mathrm{M}$ in $\mathrm{CCl}_{4}$-treated transplanted mouse liver (x200). E, DAPI staining for nucleus. F, merge of $\mathrm{D}$ and $\mathrm{E}$. Immunofluorescence staining patterns showed that positive albumin (ALB) of cytoplasmic staining and B-2M of cytoplasmic membrane staining were present in the engrafted mouse liver.



Figure 9. RT-PCR analysis of human liver-specific gene expression in transplanted mice after $\mathrm{CCl}_{4}$ treatment. Lanes 1 and 2, transplanted mouse liver; lane 3 , untransplanted mouse liver; lane 4, human liver; lane 5, hUCBderived cells.

was from days 11 to 13 of the earlier gestation was selected for the experiments. Therefore, the higher rate of chimerism in different groups of in utero primitive hematopoietic cell transplantation was achieved. These findings provide a basic model for further studies on conversion of primitive hematopoietic cells to hepatocytes and repair of liver damage induced by $\mathrm{CCl}_{4}$ in engrafted mice achieved via in utero transplantation.

In this human-mouse xenograft model, the chimerism was identified by PCR for human chromosome $17 \alpha$ satellite sequence as well as by FACS for CD34, GPA, CD14 and CD45 in peripheral blood. The results indicated that primitive hematopoietic cells in recipients could not only differentiate to multilineage progenitors, such as erythroblasts, monoblasts and myeloid progenitors, but also distribute to different hematopoietic organs. The primitive hematopoietic cells

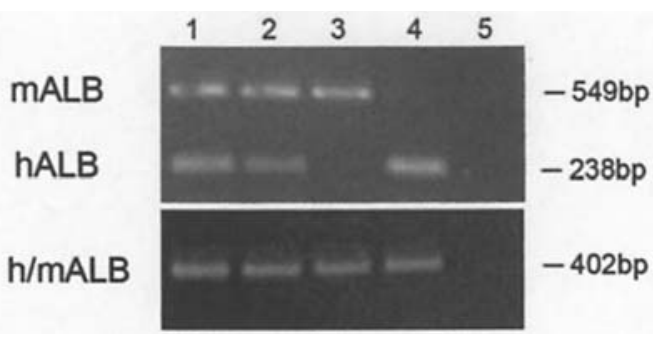

Figure 10. Human albumin mRNA was specifically expressed in engrafted mouse liver after injury by $\mathrm{CCl}_{4}$. Lanes 1 and 2, transplanted mouse liver; lane 3 , untransplanted mouse liver; lane 4, human liver; lane 5, hUCBderived cells.

Table IV. Human serum albumin in the engrafted mouse plasma.

\begin{tabular}{lc}
\hline Sample & Human serum albumin (mean) \\
\hline TM 1 & $15.6 \mathrm{mg} / \mathrm{l}$ \\
TM 2 & $1.7 \mathrm{mg} / 1$ \\
TM 3 & $2.1 \mathrm{mg} / 1$ \\
TM 4 & $3.0 \mathrm{mg} / 1$ \\
TM 5 & $1.5 \mathrm{mg} / 1$ \\
UM 1 & $0.59 \mathrm{mg} / 1$ \\
UM 1 & $0.47 \mathrm{mg} / 1$ \\
\hline
\end{tabular}

The level of human ALB in the five engrafted mice sera was from 1.5 to $15.6 \mathrm{mg} / \mathrm{l}$ by ELISA $(\mathrm{n}=3)$. It was significantly higher than that of untransplanted mice $(0.47$ or $0.59 \mathrm{mg} / \mathrm{l})$ after $\mathrm{CCl}_{4}$ treatment. In one of the engrafted mice, the level of human ALB was 26-fold that of the untransplanted mice. TM, transplanted mouse; UM, untransplanted mouse.

following in utero transplantation engrafted in the marrow environment and migrated to other hematopoietic organs by mobilization through systemic circulation. A long-term (324 days) engraftment was also found in a recent model in which the higher level of GPA expression was detectable in bone marrow, spleen and peripheral blood, similar to the reports of Yahata and Porada $(17,20)$. These results confirmed that human hematopoietic cells can remain in the recipient for a long time.

To date, the most compelling evidence for the potential of in utero stem cell transplantation has been obtained from the experiments of animal models and clinical experiences $(1,21)$. Continuous research appears likely to succeed in developing in utero transplantation into an effective form of therapy for a variety of diseases. The technology of prenatal diagnosis continues to improve allowing for greater numbers of genetic and developmental defects to be diagnosed early in gestation. Encouraging insights from recent animal studies suggest that the barriers to donor cell engraftment can be breached opening the possibility for wider clinical application of IUT in the future.

However, a very exciting and intriguing finding is that stem cells have the characteristic of plasticity. It can be visualized that a simple bone marrow aspirate could be used 
in the future to repair a patient's damaged liver, heart or skeletal muscle, nervous tissue, or possibly any somatic tissue. The plasticity provides us with groundbreaking ideas that are changing the way stem cell biologists perceive their field. Recently, Wang et al reported that purified human stem cells from bone marrow and umbilical cord blood can generate hepatocyte-like cells in the livers of immune-deficient mice (15), which provides powerful evidence for us to further explore the plasticity of adult stem cells by in utero transplantation of hematopoietic stem/progenitor cells.

The present study successfully establishes a human-mouse xenograft model by in utero transplantation of primitive hematopoietic cells. It is possible for us to use this model to observe hepatocyte regeneration from primitive hematopoietic cells, particularly in liver injured by $\mathrm{CCl}_{4}$ and uninjured liver, and to determine the fate of the engrafted human primitive hematopoietic cells in vivo. We used human $\mathrm{CD}^{2} 4^{+}$cells or MNCs from human umbilical cord blood as the starting human hematopoietic stem/progenitor cell sources in this study. Human cells were found in liver, spleen and peripheral blood of transplanted mice, which was confirmed by FACS as well as molecular detections. After one month of $\mathrm{CCl}_{4}$-induced liver damage, the human hepatocyte-like cells were observed in the recipients who received primitive hematopoietic cell transplantation in utero. Human liver-specific genes, such as albumin, AFP, HNF4, and TDO, were expressed in the recipients. These results indicated that some engrafted human cells differentiated into liver-like cells under an appropriate condition and at least partially compensated the liver function in recipient mice treated with $\mathrm{CCl}_{4}$.

Recent studies showed that adult bone marrow was identified as the potential source of hepatic progenitor cells (oval cells) (14) and hepatocytes (22-25). To identify the bone marrow cells responsible for hepatocyte lineage differentiation, Lagasse et al (16) used an inducible animal model of fumarylacetoacetate hydrolase $(\mathrm{FAH})$, a lethal hereditary liver disease. Bone marrow cells were injected into lethally irradiated $\mathrm{FAH}^{-/-}$mice. After several months of transplantation, the livers of animals restored their biochemical functions and normal weights, and presented numerous donor-derived hepatocytes. Austin et al (26) suggested that a better understanding of the various stem or progenitor cells of hepatic lineage may facilitate cellular transplantation approaches for the correction of hepatic function in patients with end-stage liver disease. In this study, the overexpression of human albumin was detectable not only in the damaged liver of the recipients with $\mathrm{CCl}_{4}$ treatment but also in their sera. Immunofluorescence data provided other proof that human hematopoietic stem/progenitor cells derived from hUCB can differentiate into hepatocyte-like cells in vivo. Therefore, it was possible that human primitive hematopoietic cells from BM or UCB could convert into injured tissue cells to restore the function of tissues or organs.

Recent reports have highlighted the differentiation potential of human cord blood cells and the generation of human hepatocytes from transplanted cord blood cells in nonobese diabetic-severe combined immunodeficient (NOD-SCID) mice $(15,27-28)$. We first established a novel model to explore the generation of human hepatocyte-like cells by in utero transplanted cord blood cells in normal mice with or without $\mathrm{CCl}_{4}$-induced liver injury. An interesting result was found in our experiments in which the generation of human hepatocytes was derived from hUCB cells between the two administrations (data not shown). In addition, human cord blood cell-derived hepatocyte-like cells expressed human albumin and human hepatocyte-specific protein HNF4 and TDO. These results indicated that hUCB-derived hepatocyte-like cells could partially restore $\mathrm{CCl}_{4}$-induced liver injury. Sharma and colleagues (29) confirmed that human cord blood cells contribute to the formation of hepatocyte-like cells more frequently than adult or neonatal mouse BM cells after being transplanted into NOD-SCID mice. Moreover, an important result was obtained in our study in which the level of albumin in sera of recipients with $\mathrm{CCl}_{4}$-induced liver injury did not decrease significantly. The other biochemical markers, such as ALT, AST, and ALP, were little increased in the experimental group and no significant difference was found comparing to the control group. These results indicated that IUT-hUCB could play an important role in partly restoring and protecting liver function from damage by $\mathrm{CCl}_{4}$.

In conclusion, the novel human-mouse chimerism model we described herein revealed a long-term engraftment of human donor cells via in utero transplantation of human hematopoietic stem/progenitor cells, and human hepatocytes can be regenerated in this chimeric animal. More significantly, the human liver-like cells generated from the engrafted cells were able to partially repair the injured liver induced by $\mathrm{CCl}_{4}$ treatment. Our findings may facilitate the therapeutic potential by in utero transplantation of hUCB primitive hematopoietic cells for liver damage, particularly for congenital liver diseases.

\section{Acknowledgments}

We especially thank Professor Yi-Tao Zeng for his valuable support and insightful discussion for this study. We also thank Professors Wen-Rong Xu and Ming Qi of Jiangsu University for their helpful critical reading of this manuscript. This study was supported by Chinese National '863' Program (grant no. 2002AA206191) and doctor grant from Shanghai JiaoTong University (grant no. BXJ0527).

\section{References}

1. Muench M: In utero transplantation: baby steps towards an effective therapy. Bone Marrow Transplant 35: 537-547, 2005.

2. Muench $M$ and Bárcena A: Stem cell transplantation in the fetus. Cancer Control 11: 105-118, 2004.

3. Owen RD: Immunologic consequences of vascular anastomoses between bovine twins. Science 102: 400-401, 1945.

4. van Dijk B, Bommsma D and de Man A: Blood group chimerism in human multiple births is not rare. Am J Med Genet 61: 264-268, 1996.

5. Picus J, Holley K, Aldrich W, Griffin JD and Letvin NL: A naturally occurring bone marrow-chimeric primate. II. Environment dictates restriction on cytolytic $\mathrm{T}$ lymphocyte-target cell interactions. J Exp Med 162: 2035-2052, 1985.

6. Milner R, Shaaban A, Kim HB, Fichter C and Flake AW: Postnatal booster injections increase engraftment after in utero stem cell transplantation. J Surg Res 83: 44-47, 1999.

7. Hayashi S, Peranteau WH, Shaaban AF and Flake AW: Complete allogeneic hematopoietic chimerism achieved by a combined strategy of in utero hematopoietic stem cell transplantation and postnatal donor lymphocyte infusion. Blood 100: 804-812, 2002.

8. Schoeberlein A, Schatt S, Troeger C, Surbek D, Holzgreve W and Hahn S: Engraftment kinetics of human cord blood and murine fetal liver stem cells following in utero transplantation into immunodeficient mice. Stem Cells Dev 13: 677-668, 2004. 
9. Turrini P, Monego G, Gonzalez J, et al: Human hepatocytes in mice receiving pre-immune injection with human cord blood cells. Biochem Biophys Res Commun 326: 66-73, 2005.

10. Zeng FY, Chen MJ, Huang WY, et al: In utero transplantation of human hematopoietic stem cells into fetal goats under B-type ultrasonographic scan: an experimental model for the study of potential prenatal therapy. Eur J Obstet Gynecol Reprod Biol 118: 170-173, 2005 .

11. Zeng FY, Chen MJ, Katsumata M, et al: Identification and characterization of engrafted human cells in human/goat xenogeneic transplantation chimerism. DNA Cell Biol 24: 403-409, 2005.

12. Shi Q, Rafii S, Wu MH, et al: Evidence for circulating bone marrow-derived endothelial cells. Blood 92: 362-367, 1998.

13. Ferrari G, Cusella-De Angelis G, Coletta M, Paolucci E, Stornaiuolo A, Cossu G and Mavilio F: Muscle regeneration by bone marrow-derived myogenic progenitors. Science 279: 1528-1530, 1998.

14. Petersen BE, Bowen WC, Patrene KD, et al: Bone marrow as a potential source of hepatic oval cells. Science 284: 1168-1170, 1999.

15. Wang X, Ge S, McNamara G, Hao QL, Crooks GM and Nolta JA: Albumin-expressing hepatocyte-like cells develop in the livers of immune-deficient mice that received transplants of highly purified human hematopoietic stem cells. Blood 101: 4201-4208, 2003.

16. Lagasse E, Connors H, Al-Dhalimy M, et al: Purified hematopoietic stem cells can differentiate into hepatocytes in vivo. Nat Med 6: 1229-1234, 2000.

17. Yahata T, Ando K, Sato T, et al: A highly sensitive strategy for SCID-repopulating cell assay by direct injection of primitive human hematopoietic cells into NOD/SCID mice bone marrow. Blood 101: 2905-2913, 2003.

18. Hayashi S, Abdulmalik O, Peranteau WH, et al: Mixed chimerism following in utero hematopoietic stem cell transplantation in murine models of hemoglobinopathy. Exp Hematol 31: 176-184, 2003.
19. Oppenheim SM, Muench MO, Ada'n AG, Moyer AL, BonDurant RH, Rowe D and Anderson GB: Hematopoietic stem cell transplantation in utero produces sheep-goat chimeras. Blood Cells Mol Dis 27: 296-308, 2001.

20. Porada GAP, Porada CD, Chamberlain J, Torabi A and Zanjani ED: Formation of human hepatocytes by human hematopoietic stem cells in sheep. Blood 104: 2582-2590, 2004.

21. Flake AW: In utero stem cell transplantation. Best Pract Res Clin Obstet Gynaecol 18: 941-958, 2004.

22. Jang YY, Collector MI, Baylin SB, Diehl AM and Sharkis SJ: Hematopoietic stem cells convert into liver cells within days without fusion. Nat Cell Biol 6: 532-539, 2004.

23. Theise ND, Badve S, Saxena R, Henegariu O, Sell S, Crawford JM and Kause DS: Derivation of hepatocytes from bone marrow cells in mice after radiation-induced myeloablation. Hepatology 31: 235-240, 2000.

24. Theise ND, Nimmakayalu M, Gardner R, et al: Liver from bone marrow in humans. Hepatology 32: 11-16, 2000.

25. Mallet VO, Mitchell C, Mezey E, et al: Bone marrow transplantation in mice leads to a minor population of hepatocytes that can be selectively amplified in vivo. Hepatology 35: 799-804, 2002.

26. Austin TW and Lagasse E: Hepatic regeneration from hematopoietic stem cells. Mech Dev 120: 131-135, 2003.

27. Newsome PN, Johannessen I, Boyle S, et al: Human cord bloodderived cells can differentiate into hepatocytes in the mouse liver with no evidence of cellular fusion. Gastroenterology 124: 1891-1900, 2003.

28. Ishikawa F, Drake CJ, Yang S, et al: Transplanted human cord blood cells give rise to hepatocytes in engrafted mice. Ann NY Acad Sci 996: 174-185, 2003.

29. Sharma AD, Cantz T, Richter R, et al: Human cord blood stem cells generate human cytokeratin 18-negative hepatocyte-like cells in injured mouse liver. Am J Pathol 167: 555-564, 2005. 